Article

\title{
Cultural "Authenticity" as a Conflict-Ridden Hypotext: Mulan (1998), Mulan Joins the Army (1939), and a Millennium-Long Intertextual Metamorphosis
}

\author{
Zhuoyi Wang \\ Department of East Asian Languages and Literatures, Hamilton College, Clinton, NY 13323, USA; \\ zwang@hamilton.edu
}

Received: 6 June 2020; Accepted: 7 July 2020; Published: 10 July 2020

\begin{abstract}
Disney's Mulan (1998) has generated much scholarly interest in comparing the film with its hypotext: the Chinese legend of Mulan. While this comparison has produced meaningful criticism of the Orientalism inherent in Disney's cultural appropriation, it often ironically perpetuates the Orientalist paradigm by reducing the legend into a unified, static entity of the "authentic" Chinese "original". This paper argues that the Chinese hypotext is an accumulation of dramatically conflicting representations of Mulan with no clear point of origin. It analyzes the Republican-era film adaptation Mulan Joins the Army (1939) as a cultural palimpsest revealing attributes associated with different stages of the legendary figure's millennium-long intertextual metamorphosis, including a possibly nomadic woman warrior outside China proper, a Confucian role model of loyalty and filial piety, a Sinitic deity in the Sino-Barbarian dichotomy, a focus of male sexual fantasy, a Neo-Confucian exemplar of chastity, and modern models for women established for antagonistic political agendas. Similar to the previous layers of adaptation constituting the hypotext, Disney's Mulan is simply another hypertext continuing Mulan's metamorphosis, and it by no means contains the most dramatic intertextual change. Productive criticism of Orientalist cultural appropriations, therefore, should move beyond the dichotomy of the static East versus the change-making West, taking full account of the immense hybridity and fluidity pulsing beneath the fallacy of a monolithic cultural "authenticity".
\end{abstract}

Keywords: Mulan; adaptation; Disney; Orientalism; cultural authenticity; cultural palimpsest; Chinese cinema

\section{Introduction}

In 1993, Disney animators encountered an impasse while working on a short feature called China Doll, a cliché-ridden story about a miserable Chinese girl rescued by a British Prince Charming. They turned to the Chinese legend of Mulan for inspiration (Whipp 1998). The earliest written record of the household legend is the anonymous Ballad of Mulan (Mulan ci or Mulan shi, henceforth Ballad), which scholars generally agree began circulating during the Northern Wei Dynasty (386-534 CE) (e.g., Hu 1928; Yu 1953; Lu and Feng 1956; You 1991; Liu 1997). Ballad characterizes Mulan as a courageous daughter. When her father is drafted into the military, she enlists in his stead, and takes to the battlefield in a uniform which conceals her gender. After a valiant ten-year tour of duty, the emperor attempts to recognize her achievement by appointing her to a high official position. However, Mulan decides to reassume the role of an ordinary woman upon returning home. Her fellow soldiers are startled when she presents herself as a female, a departure from her previous mode of dress, hairstyle, and makeup (Anonymous 1979).

The legend inspired the creation of a new model for a Disney heroine in the film Mulan (dirs. Tony Bancroft and Barry Cook, 1998). Mulan marked a departure from the standard model of a 
Disney heroine who passively awaits a prince's deliverance. In the film, Mulan is an independent and resourceful warrior who uses her intellect to surpass her male allies and overcome her male adversaries. Thanks to this change, the film successfully cashed in on the turn to "girl power" in the Western-dominated pop culture of the 1990s, and was internationally acclaimed for breaking the stereotypical female mold in mass media (e.g., Labi 1998; Chan 2002; Nguyen 2008).

As critics have pointed out, however, Mulan's progressiveness is seriously hampered by its reassertion of Western supremacy. Throughout the film, Mulan acts as a surrogate for commonly perceived Western values, such as individualism and independence, fighting to find her "true self" against restrictions imposed by a centuries-old "Chinese" patriarchy. Ironically, her apparently feminist struggle fits well into the cultural-imperialist agenda of "saving brown women from brown men" (Spivak 1993). While not incarnated in Mulan as an actual British Prince Charming, the commonly perceived Western values play the role of a savior whisking away this imagined ancient Chinese girl from her own repressive culture. Such feminism (or pseudo-feminism, as some critics call it) is particularly non-threatening to white male audiences, as it projects contemporary Western mainstream values as timeless and righteous, reducing gender oppression to the exclusive problem of non-Western cultures (Maio 1998; Ma 2003; Limbach 2013; Yin 2014).

Resisting this racial and cultural hegemony, scholars have turned to the Chinese legend of Mulan in an attempt to demarginalize oppressed narratives, memories, and imaginations. Many scholars have insightfully revealed how Disney's adaptation interpolated its stereotypical imaginings of Chinese culture into the Mulan story in order to inject it into a Western frame (Mo and Shen 2000; Djao 2002; Sun 2003; Wang and Yeh 2005; Peng 2005; Yin 2014). Such efforts at demarginalization, however, are usually flawed, owing to the general underestimation of the complexity of the transformation that the legend of Mulan has long undergone. Oversimplified and de-contextualized versions of the legend, as a result, have often been used to represent the "authentic" Chinese culture that needs to be restored after Disney's disruption. For example:

[Disney's Mulan] trivializes a people's cultural heritage by forcing the elements of the story into a Hollywood formula. In the process, the plot of the folklore, cherished by the Chinese for over a thousand years, was distorted through embellishment and omission. [... ] In the traditional story Hua Mulan joined the army in place of her father out of filial piety. She knew that it was out of question for her old and infirm father to be mobilized although he had served in the army with distinction. [ . . ] In the folklore, Hua Mulan was instructed in the martial arts and military stratagems by her father [ . . . ]. (Djao 2002) ${ }^{1}$

Such criticism ironically privileges Disney, as well as the Western culture where the media conglomerate emerges, as the sole transformer of a Chinese "traditional story" that was supposedly free from modification for over a thousand years. Already present in this brief synopsis, however, are several later Chinese interpolations into the storyline of Ballad. The depiction of Mulan's father as "old and infirm" did not exist until Song of Mulan (Mulan ge, henceforth Song), which was written by a Tang Dynasty (618-907 CE) poet Wei Yuanfu (?-771 CE) hundreds of years after Ballad (Wei 1979). Mulan did not have a family name until the Yuan Dynasty (1271-1368 CE), and no one claimed Hua as her family name until Xu Wei (1521-1593 CE), a Ming Dynasty (1368-1644 CE) intellectual who wrote the play Female Mulan Joins the Army in Place of Her Father (henceforth Female Mulan). The father's education of Mulan was also a later embellishment that first appeared in the play. Moreover, as this article will further discuss, even Ballad cannot be considered a single "original". It is rather a product of hundreds of years of transmission, adaptations, and translations of an oral folklore that probably did not even originate in the Chinese language. Consequently, it is far more mixed than just a text of "Chinese" or Confucian moral lessons. By overlooking such complexity, critics of the Orientalist paradigm risk

1 I have omitted Djao's descriptions of Disney's Mulan in comparison to the folklore. 
perpetuating the essentialization of the East as a unified entity that remains static until changed by the West.

This paper argues that the Chinese hypotext of Disney's Mulan is a thousand-year accumulation of dramatically conflicting representations of Mulan with no clear point of origin. It analyzes the Republican-era (1911-1949 CE in mainland China) film adaptation Mulan Joins the Army (Mulan congjun, dir. Bu Wancang, 1939) as a cultural palimpsest revealing attributes associated with different stages of the legendary figure's long intertextual metamorphosis, including a possibly nomadic woman warrior, a Confucian role model of loyalty and filial piety, a Sinitic deity, a focus of male sexual fantasy, a Neo-Confucian exemplar of chastity, and modern models for women serving antagonistic political interests. Similar to the previous layers of conflicting adaptations constituting the enormous hypotext, Disney's Mulan is simply another hypertext continuing Mulan's metamorphosis, and it by no means contains the most dramatic intertextual change.

\section{Traveling to the Male Domain}

In February 1939, the Xinhua Film Company released Mulan Joins the Army in Shanghai. Immense interest in the film had been generated thanks to a massive publicity campaign popularizing Chen Yunshang, a Hong Kong actress making her mandarin film debut as Mulan. Chen was depicted as a talented modern girl, well on her way to becoming a Hollywood star. Her fondness of various Western sports, ranging from tennis and bowling to horse riding, was a key focus of her public appearance (Du 1986; Fu 2003; Zhang 2004; Harris 2011).

Mulan Joins the Army opens with a scene that supported the movie star's vigorous, smart, and outdoorsy image. In this scene, Chen as Mulan rides a horse, wears androgynous attire, and hunts in the woods. A series of extreme long shots stress the openness of her hunting space. When she returns home after a very successful hunt, both of her parents scold her for her unladylike behavior. As punishment, her father forces her to stay at home and weave. Undaunted by this arrangement, Mulan playfully shoots off a visiting messenger's hat to demonstrate her hunting skills.

By injecting Chen's modern charm into Mulan, this beginning significantly departed from what the audience had known about the household legend. Despite its complex transformations and adaptations, the legend had consistently placed Mulan in domestic space at its beginning and never portrayed her as unwilling to do weaving work. Ballad, as the earliest example, begins with Mulan sitting by the loom. She pauses in her weaving only to worry about the challenge that her father's conscription has brought to her family. Song begins in the same way, with a sighing Mulan holding a shuttle in hand. In the Qing Dynasty (1644-1912 CE) opera A Tale of Two Rabbits (Shuang tu ji), Mulan stresses that "weaving is the fundamental duty (ben yao) in women's quarters" (Aixinjueluo 1776). In some other versions, such as the Qing Dynasty novels The Legend of an Extraordinary Girl Who Is Loyal, Filial, Courageous and Heroic (Zhong xiao yong lie qi nü zhuan, or Zhong xiao yong lie Mulan zhuan, henceforth Extraordinary Girl) and The Legend of A Filial and Heroic Girl in the Unusual History of the Northern Wei (Beiwei qishi gui xiao lie zhuan, henceforth Unusual History), Mulan is not only a diligent weaver, but also good at all the other types of domestic "womanly work" (nügong), such as sewing and embroidery (Anonymous 1990; Zhang 1992).

Mulan's diligence in weaving and other womanly work was a crucial part of her exemplary morality in pre-modern and especially late imperial China. As land rights fell to patrilineal inheritance, the early Chinese patriarchy allocated farming to men and textile production to women. An in-house job at the time, textile production rendered women responsible for managing the inner space, while men controlled the outer space. This division was later codified into gendered regulations through Confucian canons, such as Book of Rites (Li ji) and Instructions for Women (Nü jie). In the late imperial economy, the dominating neo-Confucianism viewed this labor division, which was collapsing at the time, as embodying the ideal social order of classical Confucianism. Mandating women to do domestic womanly work became "an essential factor in maintaining public morality" (Bray 1997, p. 128). 
The beginning of the 1939 film, however, presents a Mulan hunting in the openness of the outer space and reluctant to fulfill the "fundamental" womanly duty. By doing so, it epitomizes late Qing and Republican intellectuals' efforts to rewrite her legend and advocate women's new position in family and society. Predominantly male, many of these intellectuals saw women who adhered to traditional values and practices as a source of weakness for the nation. They argued that these women, crippled with bound feet and confined in the domestic sphere, were physically and intellectually unable to nurture and educate their children to be future citizens of a civilized China. They therefore urged a reconstruction of Chinese women along Western guidelines. Exemplary biographies of strong, ambitious, and patriotic women served as the main way to codify new female norms (Judge 2007). Mulan was a prominent figure among them. The first modern version of her legend, written by an enlightenment intellectual Liu Yazi (under the pseudonym of Yalu, which refers to the "Asian Rousseau"), appeared as early as 1904 (Yalu 1904). Interest in adaptation of the legend continued to grow during the Republican era. A Beijing opera rendition of Mulan's story, with modern concerns added by the famous artist Mei Lanfang, appeared in 1912. Before the 1939 film, Mulan's story had been adapted into two other films: Hua Mulan Joins the Army (Hua Mulan congjun, dir. Li Pingqian, 1927) and Mulan Joins the Army (Mulan congjun, dir. Hou Yao, 1928). These are just a few examples of Mulan's frequent appearances across a full spectrum of media at the time, including literature (biography, poetry, fiction, essay, speech, and scholarly research), theater, music, painting, and cinema (e.g., Anonymous 1907; Zuo 1935; Yi 1940; Ouyang 1982; Ma 1949; Xu 1945; Yutian 1945; Zhao 1945; Zhu 1948) (Figure 1).

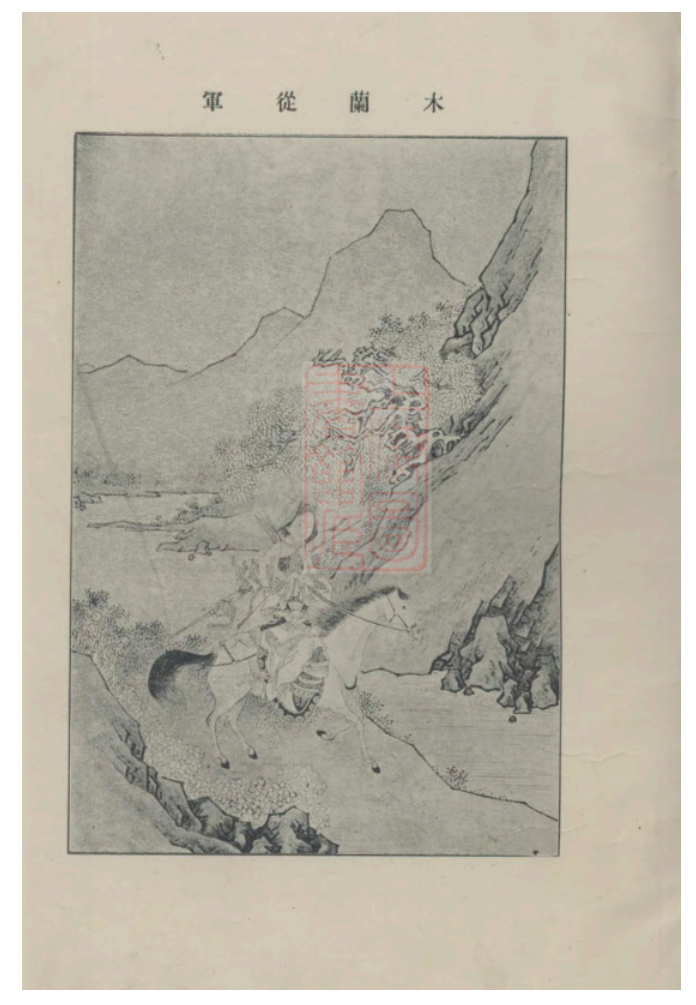

Figure 1. A painting entitled "Mulan Joins the Army (Mulan congjun)", published as an illustration for the biography of Mulan written by Liu Yazi. (Women's World, no. 3, 1904).

It was not a coincidence that the ancient Mulan was chosen to be such a major modern model for Chinese women. On the one hand, she had been a mainstream female exemplar in Chinese culture for over a thousand years. Indigenous and familiar, she could make the Western-originated gender norms seem less foreign and help stimulate national pride. On the other hand, she was also different from many other "lifeless" traditional female paragons in the eyes of Liu Yazi and other enlightenment 
intellectuals (Yalu 1904, p. 26). The difference derived from a narrative fissure of her legend since Ballad. Appearing as a typical domestic woman weaver at the beginning, Mulan somehow easily transgresses the gender boundary and demonstrates a completely different set of skills as a cross-dressed warrior fighting in the outside world. Ballad does not attach any moral worth to Mulan's decision to join the army. It simply jumps from the challenge faced by Mulan's family ("The list of summoned men comes in twelve copies: /Every copy lists my father's name!/My father has no grown-up son/And I, Mulan, I have no adult brother") to her immediate decision to leave the domestic space for military action ("I want to buy a saddle and a horse/To take my father's place and join the army"). ${ }^{2}$ The reasons for her ability and willingness to do so and her family's rationale for allowing her to do so are completely unexplained and open to many possible readings.

As the narrative fissure shows, Ballad is not a typical Confucian text as is often assumed, but ambivalent toward Confucian gender roles. The Northern Wei Dynasty, in which Ballad emerged, was not a Confucian state of the native population of China proper, or the so-called Han-Chinese, but ruled by the Xianbei, a nomadic people who conquered Northern China. It is highly possible that Ballad derived from a nomadic people's oral folklore in their language (Lan 2003; Dong 2011). If this is the case, then Mulan is probably a transliteration of a non-Chinese name (Chen 1999). The earliest existing Chinese book that includes Ballad dates to the 11th and the 12th century, which is hundreds of years after the fall of the Northern Wei Dynasty. The narrative fissure, therefore, may well be a result of Han-Chinese intellectuals' efforts to domesticate the woman warrior according to the Confucian orthodoxy through translation, adaptation, and revision during that long period of time.

Whereas we can only speculate as to what happened to Mulan's legend before it entered the existing written record, textual development since Ballad provides a clearer picture of how the legend was adapted into increasingly Confucian texts. As the earliest existing adaptation of Ballad, Song depicts Mulan's father as old and infirm from the daughter's perspective: "My father is listed in the draft's register/But his strength and energy daily wane/[ . . ] /My father has grown old, and worn by age; /How can he survive service?" By vividly foregrounding Mulan's care for her father, which is not mentioned in Ballad, the internal monologue connects Mulan's decision to join the army to a key Confucian virtue: filial piety. Since Song, filial piety became an explicit focus of Mulan's story along with a much-strengthened father-daughter connection. In Female Mulan and many later texts, Mulan's father is her educator in both literature and martial skills. Detailed descriptions of how the father teaches the daughter and/or how the daughter takes bedside care of her sick father appear in Extraordinary Girl, Unusual History, and many other works. Mulan's travel to the male domain, therefore, was deprived of its subversive potential against the Confucian gendered order. It was turned into an extension of her filial duties in the domestic space.

The 1939 film retained the strengthened father-daughter connection, yet also disrupted the traditional familial relationship. In the film, the father continues to be an educator of Mulan by teaching her martial skills, but he forbids her to use them and forces her to weave instead. Mulan continues to take care of her father when he is sick. Instead of staying at the bedside, however, she hunts so as to provide her father with game meats. The film establishes the daughter as a challenger of Confucian gender roles and the father as a defender of them, and therefore adds a tension that never existed before to their relationship. Part of Mulan's intention to join the army is therefore to break the domestic restrictions and to go outside to where she truly belongs. As a result, the film significantly blurs the Confucian focus of filial piety with a modern, Republican woman's wish of self-fulfillment.

However, if Mulan Joins the Army were driven only by a simple dichotomy of modern freedom versus traditional restrictions, Mulan would escape from the family in secret-as she does in Disney's Mulan. Instead, Mulan successfully convinces her parents and, in fact, her father first, that she should

2 Translations of Ballad, Song, Female Mulan, and lines in the 1939 film are all quoted from Kwa and Idema (2010), occasionally with slight revisions. 
join the army. As the next section will discuss, the resolution of this disagreement shows that another factor is much more important than either filial piety or self-fulfillment in the 1939 film's rationale for Mulan to join the army.

\section{Fulfilling Moral Duties}

As Joseph R. Allen points out, most versions of Mulan's legend, traditional or modern, are ultimately stories of her homecoming (Allen 1996, p. 346). The 31-line Ballad spends only three lines describing Mulan's decade-long military action, but eight lines on the moment she returns home. Song depicts Mulan's parents as being both joyful and worried when seeing their daughter return home in martial suit. Mulan then discards the military attire to assure her parents that she will be their "darling girl" again. The inculcation of the domestication process was advanced in later adaptations through a marriage of Mulan arranged by her parents (e.g., Female Mulan) or the emperor (e.g., Unusual History).

There are, however, important exceptions to this ending in both traditional and modern versions. In traditional versions, martyrdom may replace domestication as the ultimate theme. In a stone inscription drafted by Hou Youzao during the Yuan Dynasty, the emperor orders Mulan to be his concubine after learning about her true gender. Having been offered a position of minister, Mulan firmly believes that it would violate the ritual customs for an emperor to marry his official. She commits suicide to prevent that from happening. The emperor then gives her a posthumous title "filial and heroic" (xiao lie), making her a martyr of imperial morality (Huang and Li 1992, p. 21). This account inspired a number of later versions that ended in Mulan's suicide, including Extraordinary Girl (Wu 2011, pp. 43, 162-64). In modern versions, Mulan may also refuse marriage, but for different reasons. In a 1944 theatrical script by the female writer Zhao Qingge, the story ends not at Mulan's home, but on her way to a fortress. Here, Mulan refuses the advances of an army officer (who knows her true gender) but confesses her mutual love for him. Her reason for the refusal is that he is already married; for them to be together would entail his abandonment of his family, something Mulan finds reprehensible. Besides, she says, she is self-sufficient and can take care of herself without him. This unusual ending reflects a modern woman's dilemma between emotional attraction and monogamous morality as well as her ultimate decision for independence (Zhao 1945). ${ }^{3}$

Beginning with a significantly modernized Mulan, the 1939 film may seem to develop its narrative in a similar direction against the usual domestication. This would have been the case had Ouyang Yuqian, the playwright who scripted the film, followed his initial plan. Particularly impressed by the version of the legend that ends with Mulan's suicide, Ouyang wanted to characterize Mulan in a tragedy as "a woman who opposes feudalism" (a term that intellectuals used at the time to generalize the traditional Chinese culture as oppressive and backward) (Ouyang 1961, p. 54). Such a tragedy would have been, as Carolyn Fitzgerald points out, a continuation of a series of Ouyang's earlier dramas that "had focused predominantly on the depiction of tragic women who were oppressed by their 'feudal' families" (Fitzgerald 2010). However, the actual film eventually departed from this theme of gender oppression, ending with Mulan's happy marriage at home and her willingness to be an obedient wife. In the final scene, Mulan's husband victoriously claims possession of her: "Let me see where you can escape tonight!"4 In response, Mulan shyly smiles with her head lowered. The scene is clearly connected to the traditional versions in which Mulan feels inferior to her husband. In Female Mulan, for example, Mulan becomes a shy girl ashamed of her military experiences when facing her fiancé. She assures him that she will never challenge his authority.

3 Zhao might have personally experienced this dilemma and made a similar decision in her relationship with the famous writer Lao She.

4 Ending the film with the marriage was clearly Ouyang's intention. It is unclear, however, if this particular line was in Ouyang's original script or added later by someone else, such as the director Bu Wancang. This paper will discuss the difference between Ouyang and $\mathrm{Bu}$ in their approaches to the film adaptation. 
This shift in both the film's narrative trajectory and the playwright's approach to gender resulted from the historical context in which the film was produced. Beginning in 1937, Shanghai was occupied by Japan except for the so-called Solitary Island (gudao), which referred to the British, American, and French concession areas that remained intact until 1941. Xinhua was the first film company to resume Chinese film production on the Solitary Island. In 1938, Zhang Shankun, founder and manager of Xinhua, made a trip to Hong Kong and visited Ouyang, who had just fled there to avoid Japanese harassment. Zhang invited Ouyang to contribute a script of historical drama because he was afraid that a contemporary subject might spell political trouble in the besieged zone. Ouyang offered to adapt Mulan's legend and Zhang agreed. Using the ancient legend as a thinly veiled vehicle to express contemporary political concerns, Ouyang eventually decided that a happy story celebrating Mulan's "bravery and wisdom" would work better to boost the audience's morale against the invaders (Ouyang 1961, p. 54).

For this nationalist agenda, Ouyang turned his Mulan from a victim of "feudal" oppression into a loyal officer using her "bravery and wisdom" to defend a "feudal" state, the Tang Empire, against the invading nomadic enemy. The film, therefore, continued the long Confucian appropriation of Mulan, since Song, as a role model for imperial loyalty, which was defined in the frame of the distinction between Hua and Yi, or between the Sinocentric "Celestial Empire" (tianchao) and the often nomadic cultural outsiders. This was clearly not the focus of the legend at the time of Ballad, which describes the monarch's conscription as only a trouble for Mulan and her family. Ballad's glossing over Mulan's military service does not even bother to explain whom she fights for and whom she fights against. It only presents some vague clues that seem to suggest that Mulan might have participated in the century-long war between two nomadic peoples' states, the Northern Wei of Xianbei and the Khaganate of Rouran (Che 2000). Song turned the possibly nomadic Mulan into a member of Hua by having her fight the Qiang people in Khotan, where the Tang Empire fought Tibetans. At the same time, it appropriated Mulan as a surrogate of Confucian virtues set for the male "officials and sons", turning her into an educational tool urging the men to fulfill their duties in the outer space:

If in this world the hearts of officials and sons

Could display the same principled virtue as Mulan's,

Their loyalty and filial piety would be unbroken;

Their fame would last through the ages-how could it be destroyed?

Later, the escalation of Mulan's exemplary loyalty led to her deification, as seen in such examples as a stone inscription used in a village temple worshiping Mulan during the Yuan Dynasty. The ritual purpose of the stone inscription necessitated its author, Da Shian, to give Mulan a Han family name, Wei, which properly placed Mulan in a Han-Chinese patriarchal lineage (Huang and Li 1992, p. 18). Exactly which patriarchal lineage she should belong to, however, was not an easy issue to resolve. Accounts of Mulan's story during the Yuan, Ming, and Qing dynasties gave her various family names, mainly including Wei, Zhu, and Hua. Yet, no matter her surname, Mulan invariably fought for the Celestial Empire and often against nomadic enemies according to these accounts. The Hua-Yi distinction became so rigid that even Unusual History, which set Mulan's story in the Northern Wei, categorized the Xianbei empire as part of Hua, referring to it as the "Celestial Empire".

Despite having received serious blows from Western powers, the Hua-Yi distinction continued to serve as an ideological root for the emerging Chinese nationalist mentality in the modern world order. Liu Yazi, for example, hoped that a modernized China could bring about a revived Sinocentric world order. His biography of Mulan, therefore, depicts her as a warrior of the powerful Han Empire, wiping out the evil nomadic enemy. Similarly, in Mulan Joins the Army, all characters on the nomadic side appear stupid, sinister, and barbarian. In the words of Mulan's parents, these invaders are "robbers and thieves", who attack "us" for no reason. The modern analogy could not be clearer for the Chinese audience on the Solitary Island in 1939. 
Further developing the theme of loyalty, the film reconfigured the character of Mulan's father. Earlier texts tended to focus only on Mulan's loyalty, often characterizing her father as unwilling to serve in the military. In Female Mulan and Unusual History, for example, the father would rather commit suicide than go to the battlefront. In the 1939 film, however, the father decides to go to the battlefront without hesitation, stating:

Our country takes care of the troops for a thousand days in exchange for calling on troops when it needs them. Now that the country is in trouble, every civilian must go to war. How could I live off the country's support and just stay at home?

[ ... ] Fortunately, I am not that old, and I can still exert myself on behalf of my country.

It's more glorious to die on the battleground than to die at home.

It was likely a conscious wording choice of Ouyang that the father refers to the Tang Empire as "our country" or guojia, the Chinese word used to translate the Western-originated concept of the modern nation-state, rather than the "Celestial Empire". These lines were obviously written as a call for national service during the Sino-Japanese war (1937-1945 CE). Reinforcing this theme, Mulan speaks the same nationalist language on multiple occasions in the film, using the rhetoric that dying for the country would be as honorable for women as for men to quickly convince her father that she should go in place of him. As father and daughter, they resembled an ideal nationalist education that promised a solution to the on-going national crisis. As a sick old man and a young girl, they served a similar purpose as Mulan had done in those Confucian texts: urging all, and especially the men with more strength, power, and privilege, into action to fulfill their duties. The film adaptation turned the daughter and the father into similar mixtures of modern patriots and Confucian loyal subjects, resolved their disagreement, rendered the gendered boundaries in much less focus than the national ones, and bridged the narrative fissure of the rationale for Mulan's military service. Ironically, in doing so, the film in fact perpetuated the logic that had led Mulan to sacrifice her life and defend a male-defined and state-sponsored moral order.

Dressed as a man and acting as a moral example for men, however, did not spare Mulan from becoming an object of male sexual fantasy in the circulation of her story. The sexual fantasy intensified as she became a Neo-Confucian exemplar of chastity for women, and was further aroused when she appeared in modern media adaptations.

\section{Arousing Sexual Fantasy}

Like all collective works, Mulan Joins the Army reflects a compromise of different approaches in its creative team rather than any individual's unilateral vision. Quoting the well-known playwright Xia Yan, a 1940 article criticized the director Bu Wancang for altering Ouyang's script and "deteriorating" its quality (Anonymous 1940). In a 1961 memoir, Ouyang himself also complains that the film did not fully reflect his intentions because Bu focused more on "[commercial] gimmicks" (xuetou) and made a number of changes to the script. It is difficult to find out the exact changes because Ouyang's original script was never released to the public. ${ }^{5}$ However, some clues exist in the differences between the 1939 film and Ouyang's 1942 Guilin Opera (guiju) adaptation of Mulan's legend. Indeed, several scenes susceptible to the charge of "gimmick" only exist in the film, but not in the opera.

In one such scene, Mulan and a group of fellow conscripted (male) soldiers rest in an inn on their way to the army. The men are all busy washing their feet and even giving each other foot massages. Mulan, by contrast, sits quietly and does not take off her shoes. Curious about this different fellow, three men encircle Mulan. In an exaggerated manner, they bend down to examine her feet. The farce ends with Mulan nervously hurrying to another room with the foot-washing water and closing the doors behind her.

5 A script of Mulan Joins the Army was published just one month after the film's release. However, according to Ouyang, that was already the altered version (Ouyang 1961, p. 55). 
This "gimmick" is not only farcical, but full of sexual implications for its focus on Mulan's feet, which have been eroticized since Female Mulan. The 16th-century play anachronistically gives Mulan a pair of bound feet, despite setting the story in the Northern Wei, which was much earlier than the time at which foot-binding became a social custom in Neo-Confucian China. At the beginning of the play, Mulan loosens her bound feet in preparation for military service. At the same time, she contemplates a plan to re-bind her feet so that she will be suitable for marriage again after returning home:

(As she changes foot wear, she acts out pain)

Just-removed, the half-folded Tiny Ripple-Riding Socks bindings,

How it hurts!

It took me several years to bind together these "Phoenix-head sharps".

Now I quickly turn them into floating boats.

How will I now fill up these boots?

When I return, I'll still want to get married. So what can I do? Well, no need to mope about that! My family has a method for shrinking golden lotuses: just take a bit of saltpeter, boil it, and use it to wash the feet. In this way, we make them even smaller!

A series of common metaphors are employed in this vignette to both mystify and eroticize the bound feet. Lotuses, for example, were frequently used as a metaphor for bound feet because women with bound feet walked in mincing steps that evoked an illusion of dancing on floating lotuses, a symbol of purity. At the same time, lotuses had long been metaphorically associated with sex and birthing in Chinese culture. The lotus' seed-filled pod was an emblem of the fertile womb. Similar to the lotus, bound feet evoked both transcendent mystery and carnal desire (Blake 1994).

Enigmatic and arousing, bound feet were kept in the strictest privacy at the time of Female Mulan: even erotic images usually depicted women with their bindings or shoes on (Franzblau 1977; van Gulik 1961, p. 218). When Mulan verbally and gesturally unwrapped her bound feet on stage, she would likely intensify a voyeuristic pleasure for the male audience. Such voyeurism did not simply disappear after foot-binding was banned during the Republican era. Mulan Joins the Army tellingly maintains the strict privacy of Mulan's feet, connecting their exposure to the revelation of Mulan's sex and her feelings of shame and anxiety. In doing so, it created an enticing "gimmick" that objectified her feet under the male gaze both in the diegetic world and from the audience. The "gimmick" perpetuated the very obsession that underlay the foot-binding custom in opposition to Mulan's representation as an exemplar of modern woman.

Several other scenes of the 1939 film, which either do not exist in or are much more sexualized than in the Guilin Opera, also took inspiration from Female Mulan. In the 1939 film, two soldiers comment that Mulan looks "very fair and very tender". This is almost a quote from Female Mulan, where two soldiers remark that Mulan "doesn't look bad at all", "would be a nice morsel", and can be taken to "meet [their] needs". Later in the film, the two soldiers learn that Mulan's family name is Hua (which means flower in Chinese) and immediately tease her: "You really do look like a flower!" Then, they try to touch her hand. This scene was a continuation of a long tradition of using flowers as a trope for the sexualized body of Mulan (the name happens to mean wood orchid in Chinese). ${ }^{6}$ The tradition was particularly connected to Female Mulan, which not only used lotus and other flowers to repeatedly stress Mulan's sexual appeal, but, for the first time, gave her the suggestive surname Hua.

Departing from the traditional versions, Mulan Joins the Army characterizes the male characters who attempt to take advantage of Mulan as clumsy, cowardly, and laughable. Confronting the bullies,

6 The Tang poet Bai Juyi, for example, described in two poems a wood orchid tree as like a beautiful woman with heavy rouge makeup, who captivated the male poet so much that she would frequently reappear in his "spring dreams" (chunmeng, often implying sexual desire in Chinese literature). He made the reference to Mulan apparent by writing that the tree looked similar to a beautiful woman because it used to be an actual girl. See the two poems in Peng (1961, pp. 4958, 5146). 
Mulan first advises them that no countrymen should bully fellow countrymen, especially at a time of national crisis, and then teaches them a lesson with her preternatural martial arts skills. Her morality and valor later earn her the position of field marshal, which outranks all the men in the army. This also differs from the traditional versions that rank Mulan no higher than a general, retaining at least a male field marshal as her military superior.

Such a modern empowerment of Mulan, however, was also a continuation of the traditional attempt to embed Mulan's sexual appeal in her disciplinary power. In Female Mulan, for example, Mulan suffers pain only from loosening her bound feet, but not from binding or the magically easy re-binding. As Fred Blake points out, a woman's bound feet were a crucial part of her body mirroring the Neo-Confucian organization of the family. Through immense pain, foot-binding effectively disciplined a young girl's body against her primordial resistance to this organization (Blake 1994). Mulan's body, by contrast, seems to be born with this discipline so internalized that she experiences pain in the absence of regulation, rather than in the presence of it. Correspondingly, the play turns Mulan's military adventure into a demonstration of the extraordinary degree to which her hyper-disciplined body sticks to Neo-Confucian ideals for women, most importantly chastity. ${ }^{7}$ The safety of Mulan's life appears to be of no concern for either her mother or herself. The mother is only worried about whether Mulan can successfully conceal her genitalia (referred to as "you-know-what", or nahuar) when surrounded by men, and Mulan is only proud of her success in maintaining virginity in the army as promised to her mother. In the play and many later texts, including Mulan Joins the Army, Mulan's incredible and oftentimes preternatural power comes from a hyper-disciplined body, which makes her both the prototype of Neo-Confucian woman and an ideal object of male desire.

Mulan's homecoming in this context, therefore, is often accompanied by courtship from a male elite, ranging from a high-level official to the emperor. Likewise, in Mulan Joins the Army, the essential consequence of Mulan's lecturing and punishing those bullies is the attraction of her future husband Liu Yuandu (Mei Xi). Unlike in most traditional versions, where Mulan successfully conceals her true gender to comrades-in-arms until the end, Yuandu in the film gradually senses that Mulan is a woman. The film uses the classic Hollywood-style soft lighting to foreground Mulan's beauty in their increasingly romantic interactions, yet keeps her in male military regalia. The interactions reach a climax when Mulan simultaneously practices her sword and initiates an antiphon with Yuandu by singing: "When can [my beloved] enter my bosom and listen to my innermost feelings?" 8 In these scenes, Mulan's heterosexual charm is integral to and enhanced by her role as a seemingly gender-neutral hero fighting for nationalist principles.

The 1939 film's publicity campaign further projected male fantasies onto the nationalist heroine's body. When promoting the film, the Xinhua Company released two full-page pictures of its main star Chen Yunshang right next to each other in the same issue of the Xinhua Pictorial (Xinhua huabao) (Figures 2 and 3). The first picture is a film still, presenting a heroic Chen with a steadfast facial expression and a mighty posture in the full armor of Mulan. The second picture shows a feminine Chen smiling and posing in modern female dancing dress. Spreading apart her front opening skirt, Chen showcases her shapely legs and high heels (the modern alteration of a woman's natural feet to enhance sexual appeal). At the top right corner of the picture, there is a small-scale sketch of her with an added cloud (Yunshang, the star's stage name, means "cloud and [beautiful] dresses"), which depicts her as a flying fairy in a traditional Chinese painting. Mutually dependent and enhancing, the two pictures epitomize the continuity in the male construction of an ideal woman from the Neo-Confucian

7 Chastity first appeared as a theme in Mulan's legend with the rise of Neo-Confucianism during the Song Dynasty. Liu Kezhuang (1187-1269 CE), for example, stressed that Mulan returned from the battlefront "with a [morally] clean body" (Liu 1971, p. 9).

8 The original lyrics of the song use the "moonlight" to symbolize the beloved person. 
tradition into modern nationalism: she must be, at the same time, morally exemplary, transcendentally mysterious, and sexually arousing. ${ }^{9}$

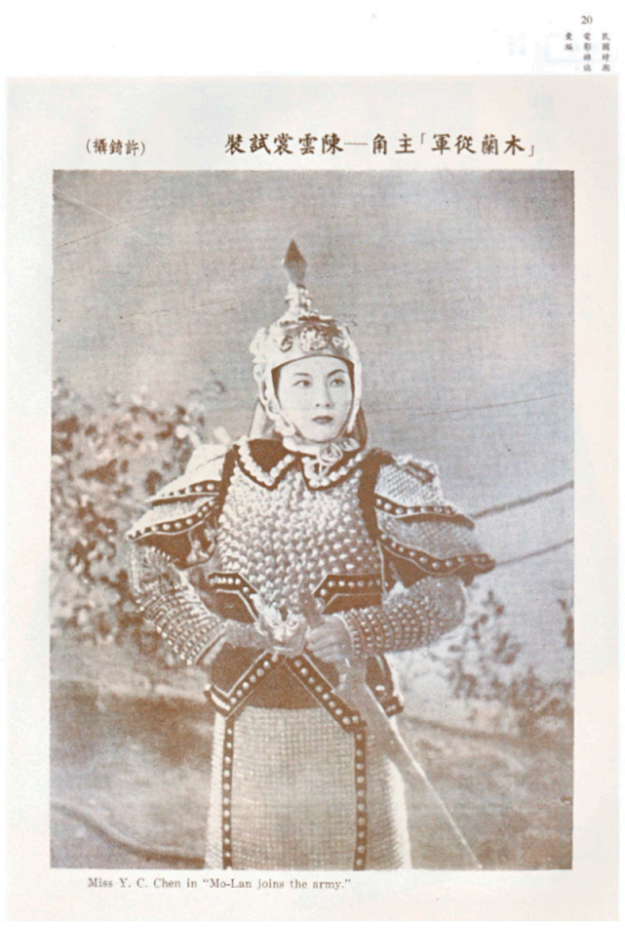

Figure 2. Film Still of Chen Yunshang as Mulan. (Xinhua Pictorial, no. 1, 1939).

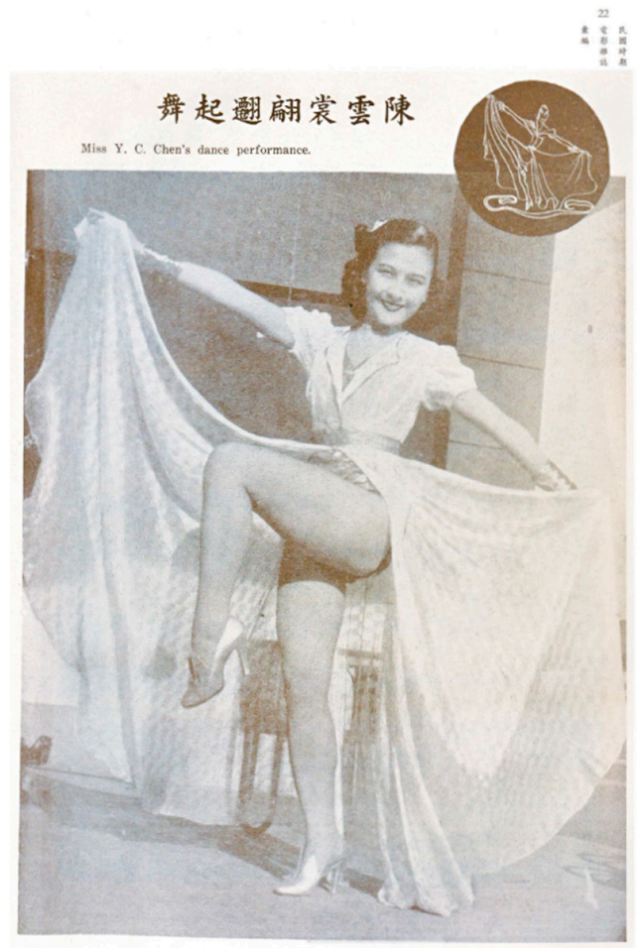

Figure 3. Picture of Chen Yunshang's dance pose. (Xinhua Pictorial, no. 1, 1939).

9 Female cross-dressing is a common theme in classical Chinese literature and opera. It is closely linked to constructions of sexual fantasy. For more discussions of this theme, see (Li 2003) and (Wing Bo Tso 2014). 


\section{Serving Conflicting Interests}

Shortly after the theatrical release of Mulan Joins the Army on the Solitary Island, the film went through a series of dramatic turns that further complicated its meaning. The person who initiated the turns was Kawakita Nagamasa, the head of the Zhonghua Movie Co. established by the Japanese military. Through this studio, the Japanese military wanted to reorganize the film industry in Shanghai to help their agenda of winning support from the "common and kind Chinese people" (as opposed to the more resistant citizens). They chose Kawakita because he had deep personal connections to China, spoke fluent Chinese, and had made films in China. Precisely for these reasons, however, Kawakita was also sympathetic with Chinese sentiments. Believing that Chinese audiences would only welcome Chinese-made feature films, he insisted that the studio act as independently as possible from the army, refrain from producing its own propagandistic feature films, and assist Chinese filmmakers in feature film production and release. He had secret meetings with Zhang Shankun, persuading him to distribute Xinhua's films through Zhonghua to the Japanese-occupied areas of China. Zhang accepted the offer after a complex political and economic calculation. Xinhua chose Mulan Joins the Army as the first film sent to Zhonghua, probably to gesture that their collaboration with the Japanese was for the righteous purpose of disseminating patriotic sentiments among the Chinese people in the occupied areas. Kawakita did not have any problem with the film, but Japanese censors did. They debated whether the film was anti-Japanese or just innocuous entertainment until a higher-ranked officer by the name of Ichiji Susumu intervened. Ichiji argued that Mulan perfectly embodied one discipline written in the Japanese Imperial Rescript on Education: "Should emergency arise, offer yourselves courageously to the state". On this ground, the film passed the censorship as a demonstration of patriotic values shared by the Japanese and the Chinese in July 1939. In 1942, the film was even released in Japan. It was not only positively reviewed by such writers as Yahara Reizaburou and Uchida Kimio, but also well received by the general Japanese public (Lin 2014, pp. 195-98, 212; Sato 2015, pp. 129-40) (Figure 4). As Sato Tadao poignantly points out, the Japanese public never treated Mulan Joins the Army as anti-Japanese, probably because the media always told them that the Japanese army was welcomed in China. They were not sensitive to the possibility that the foreign invaders in Mulan's story could stand for the Japanese (Sato 2015, pp. 141-42). In fact, the invaders in the film even began to be interpreted as Japan's enemies. For example, Women's World (Funü shijie), a magazine based in the Japanese-occupied Guangzhou, used Mulan as a major exemplar to mobilize Chinese women to join the army and defend the "Greater East Asia [Co-Prosperity Sphere]" against the United States and the British Empire (Yutian 1945).

Partially because of the Japanese appropriation of Mulan, another dramatic turn took place when the film was released in Chongqing, the war-time capital of the Republic of China, in January 1940. On the grounds that Mulan Joins the Army was "traitorous", protesters stormed the projection room of a movie theater showing the film, snatched the film print and set it on fire outside the theater. According to the protesters, the film damaged the image of the Chinese resistance force by placing the laughable bullies in Mulan's army and emphasizing her romantic life. ${ }^{10}$ They also alleged that Mulan pays homage to the Japanese sun-mark flag in the film through a song that mentions a rising sun (Sato 2015, p. 139).

As the climax of this chain of dramatic events, the burning of Mulan Joins the Army laid bare the film's sophisticated interweaving of heterogeneous and hetero-temporal traces on the millennium-old cultural palimpsest of Mulan's legend. Narrative elements that appeared politically dubious and offended the protesters, such as the bullies and the romance, indeed served mixed purposes in the film that simultaneously cast Mulan in a number of different roles: an undomesticated and independent person, a filial daughter, a loyal imperial subject, a disciplined nationalist soldier, an unmatched heroine, a woman desiring free love, a sexually appealing girl, and an ideal wife. Not only did the

10 For analyses of the complex reasons for and implications of this incident, see (Fu 2003, pp. 43-48); and (Bao 2015, pp. 1-7). 
incident expose the conflicts inherent in the mixed purposes, but it also shook the foundation of the Confucian and nationalist construction of Mulan's seemingly unquestionable Hua/Chinese identity.

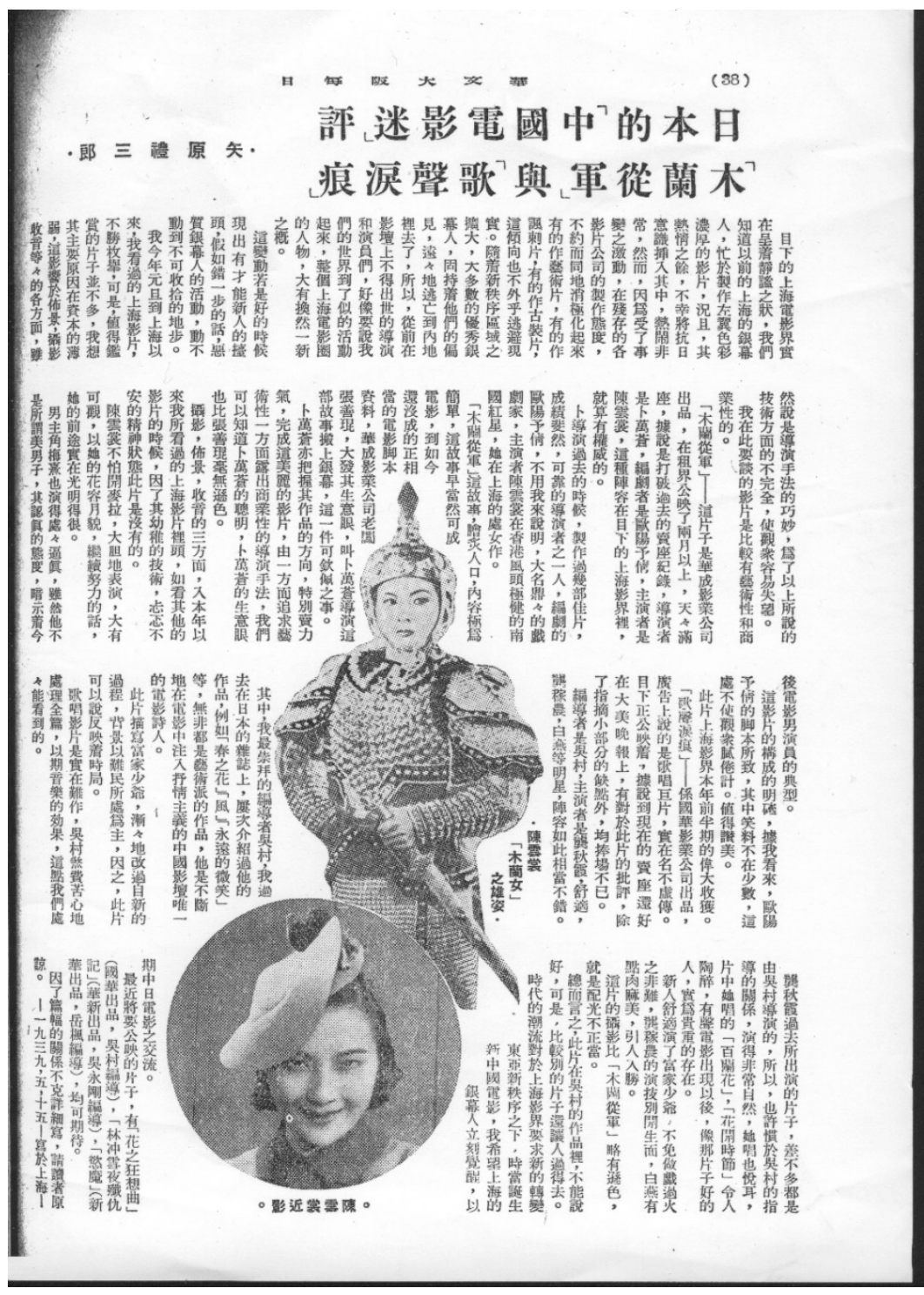

Figure 4. Yahara Reizaburou's review of Mulan Joins the Army, published in Huawen daban meiri (Osaka Daily in Chinese Language) vol. 2, no. 11, 1939. Following the popular way at the time, illustrations for this article combine Mulan's "mighty posture" ("xiongzi" in Chinese, literally "male posture") in full armor with Chen's feminine posture in modern dress.

The Republican government intervened and soon quieted the protest. The film was re-screened in Chongqing after explanations and revisions. Xinhua, for example, claimed that the song mentioning the rising sun was a Chinese folk song that had nothing to do with Japan. "To avoid misunderstanding", however, they also changed the lyrics to "the blue sky with a white sun" (qingtian bairi), the national emblem of the Republic (Zheng 2011). Apparently, the re-screened Mulan resumed her identity as a heroine defending China. However, this happened at the same time as the film, with unchanged lyrics, continued to be used as a demonstration of the Greater East Asian patriotic values in the Japanese occupied areas of China and later in Japan. Simultaneously serving two opposing sides, Mulan displayed her cultural and ideological ambiguity in an unprecedentedly dramatic manner.

Invited by such ambiguity, constant adaptations and re-interpretations of the legend produced still many more Mulans after the Confucianized Mulan, the sexualized Mulan, the Neo-Confucianized 
Mulan, the modernized Mulan, the nationalist Mulan, the traitorous Mulan, and the Greater East Asian Mulan. After the founding of the People's Republic of China in 1949, the Maoist mainland, the colonial Hong Kong, and the Republic of China that relocated its government to Taiwan all produced their own versions of Mulan's legends for different ideological and commercial purposes. ${ }^{11}$ Notably, a Republican film Junzhong fangcao (Beautiful Heroines in the Army, dir. Xu Xinfu, 1952) inserted a Beijing opera rendition of Mulan as a long dream sequence that inspired its heroine to fight the Communists. ${ }^{12}$ For the first time, the nomadic barbarians in Mulan's legend stood for an enemy that was actually Chinese, ruling China proper. The film initiated countless invocations of Mulan for the Republic's induction of women into military service defending Taiwan against the People's Republic. Lingering traces of such invocations could even be seen after the Cold War. In a Beijing Opera about Mulan produced in Taiwan during the time of the 1995-1996 Taiwan Strait crisis, for example, a character half-jokingly comments that protecting the nation should take absolute priority when the nomadic enemy is about to "fire missiles at our doorstep" (Hua Mulan, the Guoguang Opera Troupe, 1996).

Compared to these previous versions, Disney's appropriation of Mulan is nothing special. It is merely a routine continuation of the legend's long history of adaptation, which consistently epitomizes the complex interactions among diverse cultures and ideologies both within China and between the East and the West. A productive criticism of the Orientalism underlying Disney's Mulan, therefore, should move beyond the dichotomy of the static East versus the change-making West, or in this case between China and Disney. It should take into full account the immense hybridity and fluidity pulsing beneath the fallacy of a monolithic cultural "authenticity".

Funding: This research received no external funding.

Acknowledgments: I would like to particularly thank Joseph R. Allen and Carolyn Fitzgerald, both of whom have done excellent research on Mulan, for discussing this research with me and sharing their insights. I appreciate the three anonymous reviewers' very helpful comments on this paper. I am also grateful to Yomi Braester, Cooper Creagan, Alex Witonsky, and Li Yang for their helpful suggestions on the writing of the paper.

Conflicts of Interest: The author declares no conflict of interest.

\section{References}

Aixinjueluo, Yongen. 1776. Shuang tu ji (A Tale of Two Rabbits). In Yiyuan si zhong (Four Plays of Ripple Garden). Beijing: Li fu.

Allen, Joseph R. 1996. Dressing and Undressing the Chinese Woman Warrior. Positions: East Asia Cultures Critique 4: 343-79. [CrossRef]

Anonymous. 1907. Changge ji: Nü junren (A Collection of Songs: Woman Soldiers). Nüzi Shijie (Women's World) 2: 26.

Anonymous. 1940. Mulan congjun zai yu beifen shijian teji (Collected reports on the burning of Mulan Joins the Army in Chongqing). Dianying Shijie (Movie's World) 11: 16, 21, 22, 25, $27,30$.

Anonymous. 1979. Mulan Shi (Ballad of Mulan). In Yuefu Shiji (A Collection of Yuefu Poems). Edited by Guo Maoqian. Beijing: Zhonghua Shuju, pp. 373-74.

Anonymous. 1990. Zhong Xiao Yong Lie Qinü Zhuan (The Legend of an Extraordinary Girl Who Is Loyal, Filial, Courageous and Heroic), Gu Ben Xiao Shuo Ji Cheng. Shanghai: Shanghai Guji Chuban She.

Bao, Weihong. 2015. Fiery Cinema: The Emergence of an Affective Medium in China, 1915-1945. Minneapolis: University of Minnesota Press.

Blake, C. Fred. 1994. Foot-Binding in Neo-Confucian China and the Appropriation of Female Labor. Signs 19: 676-712. [CrossRef]

Bray, Francesca. 1997. Technology and Gender: Fabrics of Power in Late Imperial China. Berkeley, Los Angeles and London: University of California Press.

11 For a discussion of some of these versions, see (Harris 2011).

12 For a synopsis of this film, which is no longer existent, see (Huang 2011, pp. 116-19). 
Chan, Joseph M. 2002. Disneyfying and globalizing the Chinese legend Mulan. In In Search of Boundaries: Communication, Nation-states, and Cultural Identities: A Study of Transculturation. Edited by Joseph Man Chan and Bryce Telfer McIntyre. Westport: Ablex, pp. 225-48.

Che, Baoren. 2000. Mulan shi suoxie zhenshi shiji chu kao (An initial investigation of the historical events relevant to Ballad of Mulan). Xi'an Jiaoyu Xuebao (The Xi'an Journal of Education) 2: 29-33.

Chen, Sanping. 1999. Mulan shi zhong de 'Mulan' bing fei Han ming ("Mulan" in Ballad of Mulan is not a Han name). Lishi Yuekan (The History Monthly) 134: 98-101.

Djao, Wei. 2002. Opinion Status as Ethnic Identity in the Chinese Diaspora. Journal of Contemporary Asia 32: 363. [CrossRef]

Dong, Lan. 2011. Mulan's Legend and Legacy in China and the United States. Philadelphia: Temple University Press.

Du, Yunzhi. 1986. Zhongguo Dian Ying Qi Shi Nian (Seventy Years of Chinese Cinema). Taipei: Zhonghua Minguo Dianying Shiye Fazhan Jijinhui, Dianying Tushuguan Chubanbu.

Fitzgerald, Carolyn. 2010. Mandarin Ducks at the Battlefield: Ouyang Yuqian's Shifting Reconfigurations of Nora and Mulan. CHINOPERL Papers 29: 45-104. [CrossRef]

Franzblau, Abraham N. 1977. Erotic art of China: A Unique Collection of Chinese Prints and Poems Devoted to the Art of Love. New York: Crown Publishers.

Fu, Poshek. 2003. Between Shanghai and Hong Kong: The Politics of Chinese Cinemas. Stanford: Stanford University Press. Harris, Kristine. 2011. Modern Mulans: Reimagining the Mulan Legend in Chinese Film, 1920s-60s. In The New Woman International: Representations in Photography and Film from the 1870s through the 1960s. Edited by Elizabeth Otto and Vanessa Rocco. Ann Arbor: University of Michigan Press.

Hu, Shi. 1928. Baihua Wenxue Shi (A History of Vernacular Literature). Shanghai: Xinyue Shudian.

Huang, Canzhang, and Shaoyi Li. 1992. Hua Mulan Kao (An Investigation of Hua Mulan). Beijing: Zhongguo Guangbo Dianshi Chubanshe.

Huang, Ren. 2011. Wang Jue: Jiushi Nian De Rensheng Yingju Zhi Lü (Wang Jue, a Career of Film and TV Artist for 90 Years). Taipei: Xiuwei Zixun Keji Gufen Youxian Gongsi.

Judge, Joan. 2007. Expanding the Feminine/National Imaginary: Social and Martial Heroines in Late Qing Women's Journals. Jindai Zhongguo Funü Shi Yanjiu (Research on Women in Modern Chinese History) 15: 16-17, 27.

Translated and Edited by Shiamin Kwa, and Wilt L. Idema. 2010, Mulan: Five Versions of a Classic Chinese Legend with Related Texts. Indianapolis: Hackett Pub. Co.

Labi, Nadya. 1998. Feminism: Girl Power. Time 151: 61-62.

Lan, Feng. 2003. The Female Individual and the Empire: A Historicist Approach to Mulan and Kingston's Woman Warrior. Comparative Literature 55: 229-45. [CrossRef]

Li, Siu Leung. 2003. Cross-Dressing in Chinese Opera. Hong Kong: Hong Kong University Press.

Limbach, Gwendolyn. 2013. "You the Man, Well, Sorta": Gender Binaries and Liminality in Mulan. In Diversity in Disney Films: Critical Essays on Race, Ethnicity, Gender, Sexuality and Disability. Edited by Johnson Cheu. Jefferson and London: McFarland \& Company, Inc.

Lin, Chang. 2014. Yanmo de Beihuan: Zhonglian Huaying Dianying Chutan (Forgotten Sentiments: A Study of the Films of Zhonglian and Huaying Studios). Hong Kong: Zhonghua shuju.

Liu, Dajie. 1997. Zhongguo Wenxue Fazhan Shi (A History of the Development of Chinese Literature). Shanghai: Shanghai Guji Chubanshe.

Liu, Kezhuang. 1971. Houcun Shihua (Houcun Notes on Poetry). Taipei: Guangwen shuju.

Lu, Kanru, and Yuanjun Feng. 1956. Zhongguo Shishi (A History of Chinese Poetry). Beijing: Zhonghua Shuju.

Ma, Shaobo. 1949. Mulan Congjun (Mulan Joins the Army). Shanghai: Xinhua Shudian. First published in 1943.

Ma, Sheng-Mei. 2003. Mulan Disney, It's Like, Re-Orients: Consuming China and Animating Teen Dreams. In The Emperor's Old Groove: Decolonizing Disney's Magic Kingdom. Edited by Brenda Ayres. New York: P. Lang, pp. 149-64.

Maio, Kathi. 1998. Disney's Dolls. New Internationalist 308: 12.

Mo, Weimin, and Wenjun Shen. 2000. A Mean Wink at Authenticity: Chinese Images in Disney's Mulan. The New Advocate 13: 129-42.

Nguyen, Mimi. 2008. Who's Your Heroine? Negotiating Asian American superpower in Disney's Mulan. Available online: https://web.archive.org/web/20080218080321/http://www.poppolitics.com/articles/2001/01/ 05/Whos-Your-Heroine\#mimi (accessed on 28 June 2020). 
Ouyang, Yuqian. 1961. Dianying banlu chujia ji (Memories of a Film Career That Began Midway). Dianying yishu (Film art) 2: 54-64.

Ouyang, Yuqian. 1982. Mulan congjun (gui ju) (Mulan Joins the Army (the Guilin opera)). In Ouyang Yuqian xi qu xuan (Selected Operas of Ouyang Yuqian). Changsha: Hunan Renmin Chubanshe. First published in 1942.

Peng, Baoliang. 2005. Reading Mulan, Viewing Mulan and Mythologizing Mulan: A Comparative Study of Chinese and American Cultures. Zhongxi Wenhua Yanjiu (Study of Sino-Western Culture) 8: 129-41.

Peng, Dingqiu, ed. 1961. Quan Tangshi (Complete Tang Poems). Taipei: Fuxing shuju.

Sato, Tadao. 2015. Paosheng Zhong de Dianying: Zhong Ri Dianying Qianshi (Filmmaking Amidst Roars of Guns: A Pre-History of Sino-Japanese Cinema). Translated by Yue Yuankun. Beijing: Shijie Tushu Chuban Gongsi.

Spivak, Gayatri Chakravorty. 1993. Can the Subaltern Speak? In Colonial Discourse and Post-Colonial Theory: A Reader. Edited by Patrick Williams and Laura Chrisman. Harvester: Hemel Hempstead.

Sun, Chyng Feng. 2003. Ling Woo in Historical Context: The New Face of Asian American Stereotypes on Television. In Gender, Race, and Class in Media: A Text-Reader. Edited by Gail Dines and Jean McMahon Humez. Thousand Oaks: Sage Publications, pp. 656-64.

van Gulik, Robert Hans. 1961. Sexual Life in Ancient China; A Preliminary Survey of Chinese Sex and Society from ca. 1500 B.C. till 1644 A.D.. Leiden: Brill.

Wang, Georgette, and Emilie Yueh-yu Yeh. 2005. Globalization and Hybridization in Cultural Products: The Cases of Mulan and Crouching Tiger, Hidden Dragon. International Journal of Cultural Studies 8: 175-93. [CrossRef]

Wei, Yuanfu. 1979. "Mulan Ge" (Song of Mulan). In Yuefu Shiji (A Collection of Yuefu Poems). Edited by Guo Maoqian. Beijing: Zhonghua Shuju, pp. 374-75.

Whipp, Glenn. 1998. Mulan Breaks the Mold with Girl Power; Newest Heroine is Not Typical Disney Damsel Waiting for Her Prince to Come. Daily News, June 19, p. L7.

Wing Bo Tso, Anna. 2014. Female Cross-Dressing in Chinese Literature Classics and Their English Versions. International Studies: Interdisciplinary Political and Cultural Journal 16: 111-24. [CrossRef]

Wu, Yazhen. 2011. Qingdai Mulan Congjun Xiaoshuo Yanjiu (A Research on the Novels of Mulan Joins the Army during the Qing Dynasty). M.A. thesis, Department of Chinese Literature, National Tainan University, Tainan, Taiwan.

Xu, Ruhui. 1945. Mulan Congjun (Mulan Joins the Army). Chongqing: Zhongguo Xiongdi Chuban Shiye Gongsi.

Yalu. 1904. Zhongguo Diyi Nü Haojie Nü Junrenjia Hua Mulan Zhuan (Biography of China's Premiere Female Hero and Female Soldier, Hua Mulan). Nüzi Shijie (Women's World) 3: 25-32.

Yi, Qiao. 1940. Jinguo Yingxiong (Heroines). Shanghai: Chaofeng Chubanshe.

Yin, Jing. 2014. Popular Culture and Public Imaginary: Disney Vs. Chinese Stories of Mulan. In The Global Intercultural Communication Reader. Edited by Molefi Kete Asante, Yoshitaka Miike and Jing Yin. New York: Routledge, pp. 285-304.

You, Guoen. 1991. Zhongguo Wenxue Shi (A History of Chinese Literature). Beijing: Renmin Wenxue Chubanshe. Yu, Guanying. 1953. Yue Fu Shi Xuan (Selection of Yuefu Poems). Beijing: Beijing Renmin Wenxue Chubanshe.

Yutian. 1945. Cong Hua Mulan Tan Dao Canzhan Funü (On Hua Mulan and Women Joining the War). Funü Shijie 52: 13. Zhang, Shaoxian. 1992. Beiwei Qishi Gui Xiao Lie Zhuan (The Legend of a Filial and Heroic Girl in the Unusual History of the Northern Wei). Shanghai: Shanghai Guji Chubanshe.

Zhang, Wei. 2004. Qian Chen Ying Shi: Zhongguo Zaoqi Dianying de Linglei Saomiao (Dust of Bygone Movies: Another Type of Sweep through Early Chinese Cinema). Shanghai: Shanghai Cishu Chubanshe.

Zhao, Qingge. 1945. Hua Mulan congjun (Hua Mulan joins the army). In Yu Da Li Hua, You Ming, Huo (Rain Falling on the Pear Blossoms, or to Live). Chongqing: Funü Yuekan She.

Zheng, Jianjian. 2011. Kongjian Yu Shijue Zhengzhi: Mulan Congjun Jiaopian Bei Fen Shijian Shimo (Space and Visual Politics: On the Incident of the Burning of Mulan Joins the Army). In Dianying Yu Dushi: Dushi Jingyan, Shijue Kongjian Yu Dianying Xiaofei (Cinema and City: Urban Experiences, Visual Spaces, and Filmic Consumption). Edited by Xihe Chen and Wangli Huang. Beijing: Zhongguo Dianying Chubanshe, pp. 169-70.

Zhu, Xi'an, ed. 1948. Mulan Congjun (Mulan Joins the Army). Shanghai: Zhonghua Shuju. Zuo, Ganchen. 1935. Mulan Congjun (Mulan Joins the Army). Shanghai: Qizhi chubanshe.

(C) 2020 by the author. Licensee MDPI, Basel, Switzerland. This article is an open access article distributed under the terms and conditions of the Creative Commons Attribution (CC BY) license (http://creativecommons.org/licenses/by/4.0/). 